\begin{tabular}{|l|l|l|}
\hline H. & Hidetsugu & Ueyama \\
\hline T. & Toshihide & Kumamoto \\
\hline K. & Keiko & Asahara \\
\hline S. & Susumu & Watanabe \\
\hline Y. & Yukio & Ando \\
\hline S. & Shuji & Mita \\
\hline M. & Masayuki & Ando \\
\hline
\end{tabular}

First Department of Internal Medicine, Kumamoto University School of Medicine, Kumamoto, Japan

\title{
Hereditary Motor and Sensory Neuropathy Type V with Spinal Cord Atrophy on Magnetic Resonance
} Imaging

\section{Key Words}

Hereditary motor and sensory neuropathy

Spinal cord atrophy

Magnetic resonance imaging

H. Ueyama, MD, First Department of Internal Medicine, Kumamoto University School of Medicine, Honjo 1-1 1, Kumamoto 860 (Japan)

Hereditary motor and sensory neuropathy (HMSN) type V, labelled by Dyck [1] in 1984 , is a rare congenital neuropathy with spastic paraplegia. We herein report such a family presenting with spinal cord atrophy on magnetic resonance imaging (MRI). The proband was a 47-year-old man who had atrophy of his lower limbs since 2 years of age. At age 30, he could not walk without aid and complained of muscle cramps. Although his parents had no symptoms, his younger brother and his aunt also suffered from difficulty in walking, suggesting autosomal dominant inheritance. Neurological examination revealed muscle weakness and wasting predominantly in the distal part of the lower limbs, showing stork leg appearance, hammer toes, and pes cavus (fig. 1). The consistency of the muscles was increased and fasciculation was observed on the feet. The deep tendon reflexes were normal in the upper limbs but absent in the lower. Extensor plantar responses were positive bilaterally. Superficial sensation was mildly decreased below the ankle, and deep sensation was severely impaired on the feet. He showed spastic as well as steppage gait, and Romberg's sign was also positive. Routine laboratory tests were normal except serum

creatine kinase was mildly elevated. Hormonal functions, blood lactate and pyruvate, plasma very-long-chain fatty acids, and cerebrospinal fluid (CSF) constituents were all normal. Serum anti-HTLV-1 antibody was negative.

Electrophysiological studies showed delayed motor conduction velocities (MCV) in the right posterior tibial nerve $(36.3 \mathrm{~m} / \mathrm{s})$ with normal MCV in the right median nerve $(60.9 \mathrm{~m} / \mathrm{s})$. The sensory action potential and conduction velocity on the right sural nerve were decreased to $1.6 \mathrm{p} . \mathrm{V}$ and $35.8 \mathrm{~m} / \mathrm{s}$, respectively. Ti-weighted sagittal and axial views of spinal MRI revealed moderate atrophy of the lower 
cervical and thoracic spinal cord (fig. 2). T2- or proton-density-weighted MRI revealed no abnormal intensity lesions. There was no hypertrophy of the nerve roots as seen in HMSN type 1 [2]. A cross-section of the sural nerve revealed a decrease in the large myelinated fibers, but neither onion-bulb formation nor endoneurial edema. Teased fiber preparations showed segmental remyelination. The unmyelinated fiber density was normal.

His 45-year-old brother began to drag his right foot at age 40. Neurological examination revealed mild muscle weakness and hyperactive deep tendon reflexes with extenso

plantar responses in the lower limbs. His gait was spastic. MRI showed a milder atrophy of the spinal cord than in the proband.

The clinical profiles of the reported proband show autosomal dominant motorsensory neuropathy with pyramidal features since infancy. These features are consistent with the diagnosis of 'HMSN type V by Dyck [1], and 'peroneal muscular atrophy with pyramidal features' by Harding and Thomas [3].

To our knowledge, this is the first report on spinal MRI of HMSN type V. Our cases showed evidence of lower cervical and whole thoracic spinal cord atrophy on $\mathrm{Tj}$ weighted imaging. On MRI, spinal cord atrophy has been observed in spinal cord injury, adre-nomyeloneuropathy, multiple sclerosis, HTLV-1-associated myelopathy, and spinal dysraphism, among others [4-7], but there have been no reports on HMSN. The MRI findings in our cases seem to correspond with the autopsy finding of chronic progressive demyelination of the corticospinal tract and posterior columns [8].

In summary, spinal cord atrophy on MRI, in addition to clinical and sural nerve findings, may be helpful in diagnosing patients with suspected HMSN type V. 


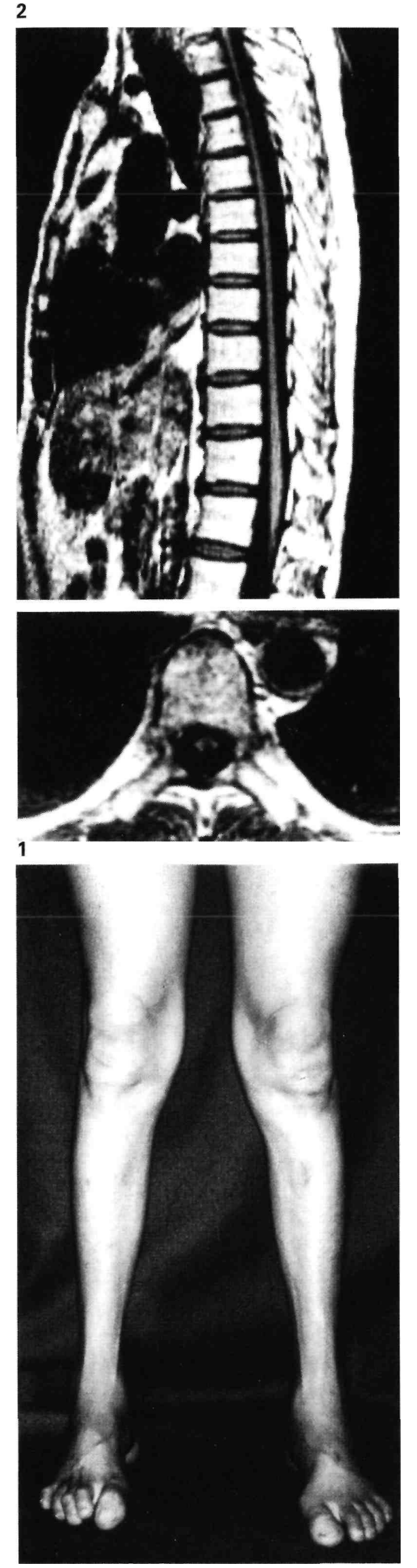


Fig. 1. Lower limbs of the proband showed a stork leg appearance with foot deformities.

Fig. 2. Top: $\mathrm{T}_{\mathrm{f}}$ weighted, sagittal MRI of the proband shows lower cervical and thoracic spinal cord atrophy. Bottom: $\mathrm{T}$

weighted, axial MRI at the $\mathrm{Th}_{\underline{\underline{s}}}$ vertebral level.

\section{References}

1 Dyck PJ: Inherited neuronal degeneration and atrophy affecting peripheral motor, sensory, and autonomic neurons; in Dyck PJ, Thomas PK, Lambert EH, Bunge R (eds): Peripheral Neuropathy, ed 2. Philadelphia, Saunders, 1984,|pp 1600-1642. 2 Rosen SA, Wang H, Cornblath DR, Uematsu S, Hurko O: Compression syndromes due to hypertrophic nerve roots in hereditary motor sensory neuropathy type I. Neurology 1989,39: 1173-1177.

Harding AE, Thomas PK: Peroneal muscular atrophy with pyramidal features. J Neurol Neurosurg Psychiatry 1984;47:168-172

4 Kerslake RW, Jaspan T, Worthington BS: Magnetic resonance imaging of spinal trauma. BrJ Radiol 1991;64:386-402. 5 Snyder RD, King JN, Keck GM, Orrison WW: MR imaging of the spinal cord in 23 subjects with ALD-AMN complex. Am J Neuroradiol 1991;12:1095-1098.

6 Honig LS, Sheremata WA: Magnetic resonance imaging of spinal cord lesions in multiple sclerosis. J Neurol Neurosurg Psychiatry 1989;52: 459-466.

7 Szalay EA, Roach JW, Smith H, Maravilla K, Partain CL: Magnetic resonance imaging of the spinal cord in spinal dysraphisms. J Pediatr Orthop 1987;7:541-545.

Serratrice G, Pellisier JF, Desnuelle C, Pouget J, Peragallo E: Familial spastic paraplegia with peroneal atrophy ( 9 cases); in Lovelace RE, Shapiro HK (eds): Charcot-Marie-Tooth disorders. Pathophysiology, Molecular Genetics, and Therapy. New ork, Wiley-Li ss 1990, pp 59-64. 